\title{
A Five-Century Reconstruction of Hawaiian Islands Winter Rainfall $\mathscr{\not}$
}

\author{
HENRY F. DIAZ \\ NOAA/ESRL, and Cooperative Institute for Research in Environmental Sciences, \\ University of Colorado Boulder, Boulder, Colorado \\ EUGENE R. WAHL \\ NOAA/National Centers for Environmental Information/Center for Weather and \\ Climate/Paleoclimatology Group, Boulder, Colorado \\ EDUARDO ZORITA \\ Institute for Coastal Research, Helmholtz-Zentrum Geesthacht, Hamburg, Germany \\ THOMAS W. GiambeLLUCA \\ Department of Geography, University of Hawai'i at Mānoa, Honolulu, Hawaii \\ JON K. EISCHEID \\ NOAA/ESRL, and Cooperative Institute for Research in Environmental Sciences, \\ University of Colorado Boulder, Boulder, Colorado
}

(Manuscript received 18 November 2015, in final form 4 May 2016)

\begin{abstract}
Few if any high-resolution (annually resolved) paleoclimate records are available for the Hawaiian Islands prior to $\sim 1850 \mathrm{CE}$, after which some instrumental records start to become available. This paper shows how atmospheric teleconnection patterns between North America and the northeastern North Pacific (NNP) allow for reconstruction of Hawaiian Islands rainfall using remote proxy information from North America. Based on a newly available precipitation dataset for the state of Hawaii and observed and reconstructed DecemberFebruary (DJF) sea level pressures (SLPs) in the North Pacific Ocean, the authors make use of a strong relationship between winter SLP variability in the northeast Pacific and corresponding DJF Hawaii rainfall variations to reconstruct and evaluate that season's rainfall over the period 1500-2012 CE. A general drying trend, though with substantial decadal and longer-term variability, is evident, particularly during the last $\sim 160$ years. Hawaiian Islands rainfall exhibits strong modulation by El Niño-Southern Oscillation (ENSO), as well as in relation to Pacific decadal oscillation (PDO)-like variability. For significant periods of time, the reconstructed large-scale changes in the North Pacific SLP field described here and by construction the long-term decline in Hawaiian winter rainfall are broadly consistent with long-term changes in tropical Pacific sea surface temperature (SST) based on ENSO reconstructions documented in several other studies, particularly over the last two centuries. Also noted are some rather large multidecadal fluctuations in rainfall (and hence in NNP SLP) in the eighteenth century of undetermined provenance.
\end{abstract}

Supplemental information related to this paper is available at the Journals Online website: http://dx.doi.org/10.1175/JCLI-D-150815.s1.

Corresponding author address: Henry F. Diaz, Department of Geography, University of Hawai'i at Mānoa, Honolulu, HI 96822. E-mail: hfdiaz@hawaii.edu

\section{Introduction}

In the Hawaiian Islands, steady trade winds interacting with mountainous topography generate significant amounts of rainfall throughout the year. A greater fraction of the annual rainfall total falls during the months of November-April (Giambelluca et al. 2013), when occasional winter storms (known as Kona

DOI: 10.1175/JCLI-D-15-0815.1 
lows) and more frequent frontal passages are evident (Kodama and Barnes 1997; Otkin and Martin 2004) and rainfall variability is high at annual to decadal time scales (Chu and Chen 2005; Diaz and Giambelluca 2012, hereafter DG12).

A number of studies have shown that winter season precipitation is strongly modulated by changes in El NiñoSouthern Oscillation (ENSO) and its low-frequency counterpart, the Pacific decadal oscillation (PDO; Chu 1989; Chu and Chen 2005; DG12; Longman et al. 2015). The strong association between the strength of the seasonal North Pacific low pressure patterns and Hawaiian Islands rainfall is illustrated in Fig. 1, which shows the mean sea level pressure (SLP) anomaly for the 10 driest and 10 wettest winters in the past 60 years. Many of these dry winters coincided with relatively strong El Niño events, while several of the wet winters occurred during La Niña conditions. DG12 include a listing of ENSOrelated years and also of decadal-scale periods that were relatively dry or wet during the available instrumental record. Among the driest winters in the modern record are the strong El Niños of 1982/83, 1991/92, 1997/98, 2002/03, and 2009/10, as well as the current 2015/16 strong El Niño. More recent wet La Niña winters occurred in 1950/51, 1967/68, 1970/71, and 1988/89.

The rainfall data for Hawaii come from a newly available compilation based on as many station records as could be assembled. Over 2000 rain gauge stations were initially considered, but because of length of record and other issues $\sim 1100$ stations were used in the final compilation (see Fig. 1 in Frazier et al. 2016). This set of digital maps allows estimation of the area-averaged monthly rainfall time series for the state of Hawaii as a whole and for each of the major islands [Kauai, Oahu, Maui, and Hawaii (known as the Big Island)] for the period 1920-2012. Figure 2 gives the time series for the 3 -month core of the winter season [December-February (DJF); Fig. 2, top] and for the nominal wet season of November-April (Fig. 2, bottom). For this study, the rainfall time series for the state as a whole for the core wet season months of DJF is used to develop a regression model against the historical SLP field for the North Pacific. This model is applied to extend the estimated rainfall time series using a new dataset of reconstructed SLP fields for the 1500-1980 period.

We know of no high-resolution (annually resolved) paleoclimate records available for Hawaii that cover the last $\sim 500$ years. Some promising work has been done with māmane trees (Sophora chrysophylla) showing a reasonable connection to regional rainfall for the last $\sim 130$ years, but results are still in development (Schubert 2013). A recent study with a high-resolution regional climate model (Zhang et al. 2016) illustrates the difficulty of simulating Hawaiian Islands rainfall and the need for very high spatial resolutions to properly simulate the spatial and temporal patterns. Our approach follows that of Timm and Diaz (2009) and Elison Timm et al. (2015) - namely, the use of synoptic-scale atmospheric circulation pattern information to infer changes in rainfall in Hawaii. The strongest association occurs during the nominally wet winter season of November through April, but the rainfall during the DJF period is strongly correlated with the 6-month values $(r=0.82$; cf. Fig. 2). Since the reconstructed SLP fields are for the DJF period, we restrict ourselves to this 3-month season.

\section{Methods and data}

\section{a. Reconstruction of DJF sea level pressure}

Values of DJF SLP reconstructions (rSLP) for the northeastern North Pacific (NNP) over the past $\sim 500$ years were derived using an analog method (Schenk and Zorita 2012; Ohlwein and Wahl 2012; Zorita and von Storch 1999), which objectively compares gridded reconstructions of summer soil moisture, as represented by the North American drought atlas (NADA; Cook et al. 2007), February-March (FM) surface temperature in temperate western North America (Wahl et al. 2014), and water-year (WY; October through the following September) precipitation based on reconstructed streamflow records in western North America as described in Diaz and Wahl (2015) to the same variables in the last-millennium transient-forcing simulation of the Max Planck Institute (MPI) Earth System Model-P (MPI-ESM-P). MPI-ESM-P is one of the participating simulation platforms in phase 5 of the Climate Model Intercomparison Project (CMIP5; Giorgetta et al. 2013). The atmospheric model is spectral with a horizontal resolution of T63, corresponding to about 1.875 degrees longitude $\times 1.875$ degrees latitude. It was selected for use because it employs the same model version for both the past-millennium (until 1850) and "historical" (since 1850) runs, it is integrated at a relatively high spatial resolution compared to other models that contributed CMIP5 simulations over the past millennium, and it has shown high quality in terms of simulation realism (Goosse et al. 2015). A list of acronyms, descriptions, and sources for key variables referred to in this paper is given in Table 1 .

The physical rationale for the choice of the three predictors noted above is that all three western North American climate variables are directly influenced by the winter atmospheric circulation over the NNP and adjacent North America and thus provide a high-quality predictor variable set to identify NNP surface pressure 
NCEP/NCAR Reanalysis

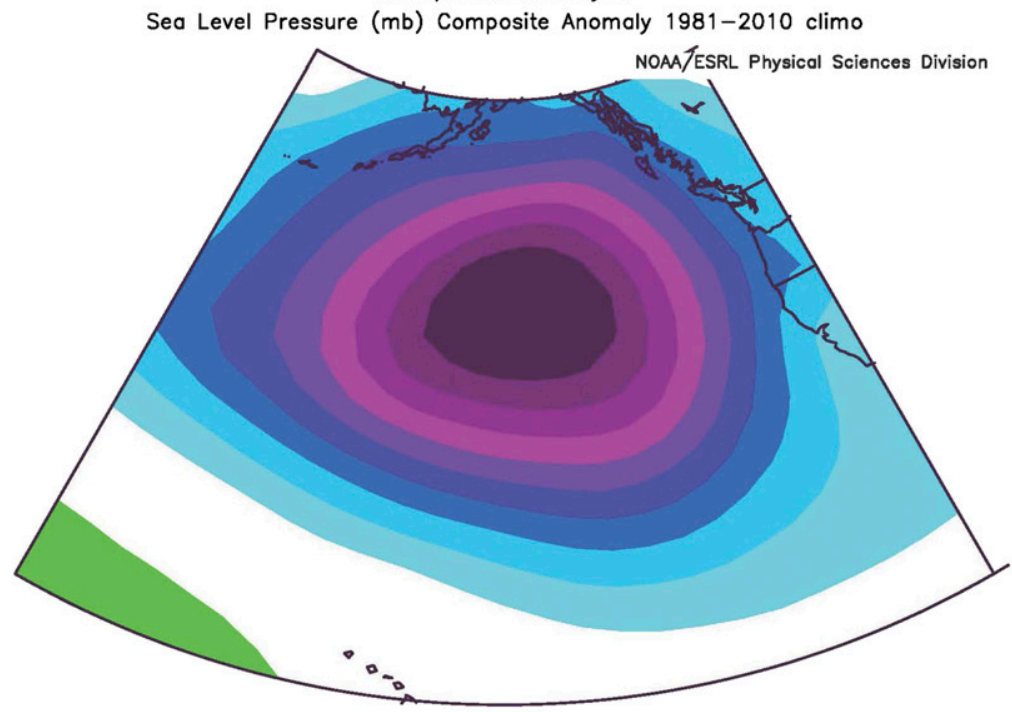

Dec to Feb: $1973,1978,1981,1992,1995,1984,1983,1998,2003,2007$
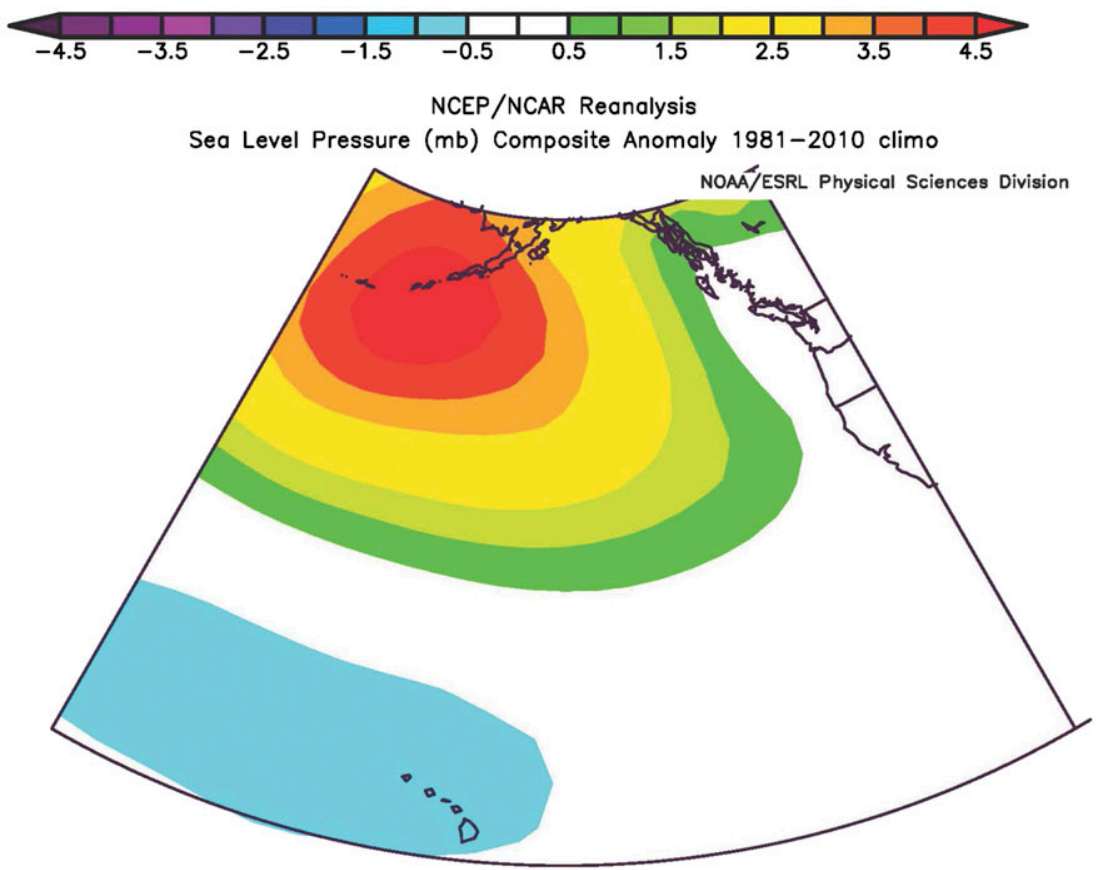

Dec to Feb: $1982,1969,1989,1979,1980,1968,1971,1991,1956,1955$

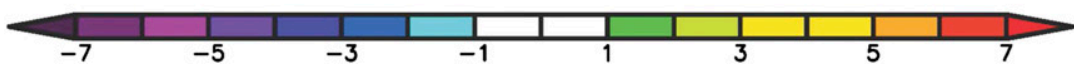

FIG. 1. Sea level pressure anomaly maps for the (top) 10 driest and (bottom) 10 wettest winter (December-February) seasons in the Hawaiian Islands. The anomalous SLP centers in the North Pacific for these marked dry and wet years are somewhat displaced but retain significant overlap. Note the difference in scale.

analogs from the model output in the absence of circulation-related proxies in the NNP region.

In the analog process, the years for which the MPIESM-P seasonal fields are more similar to the gridded predictor reconstructions are considered the "analog years." The atmospheric circulation (the predictand) of the corresponding winter seasons, averaged over the analog years, is identified as the "reconstruction." Using 
Hawaii DJF Rainfall (Avg $=506 \mathrm{~mm})$
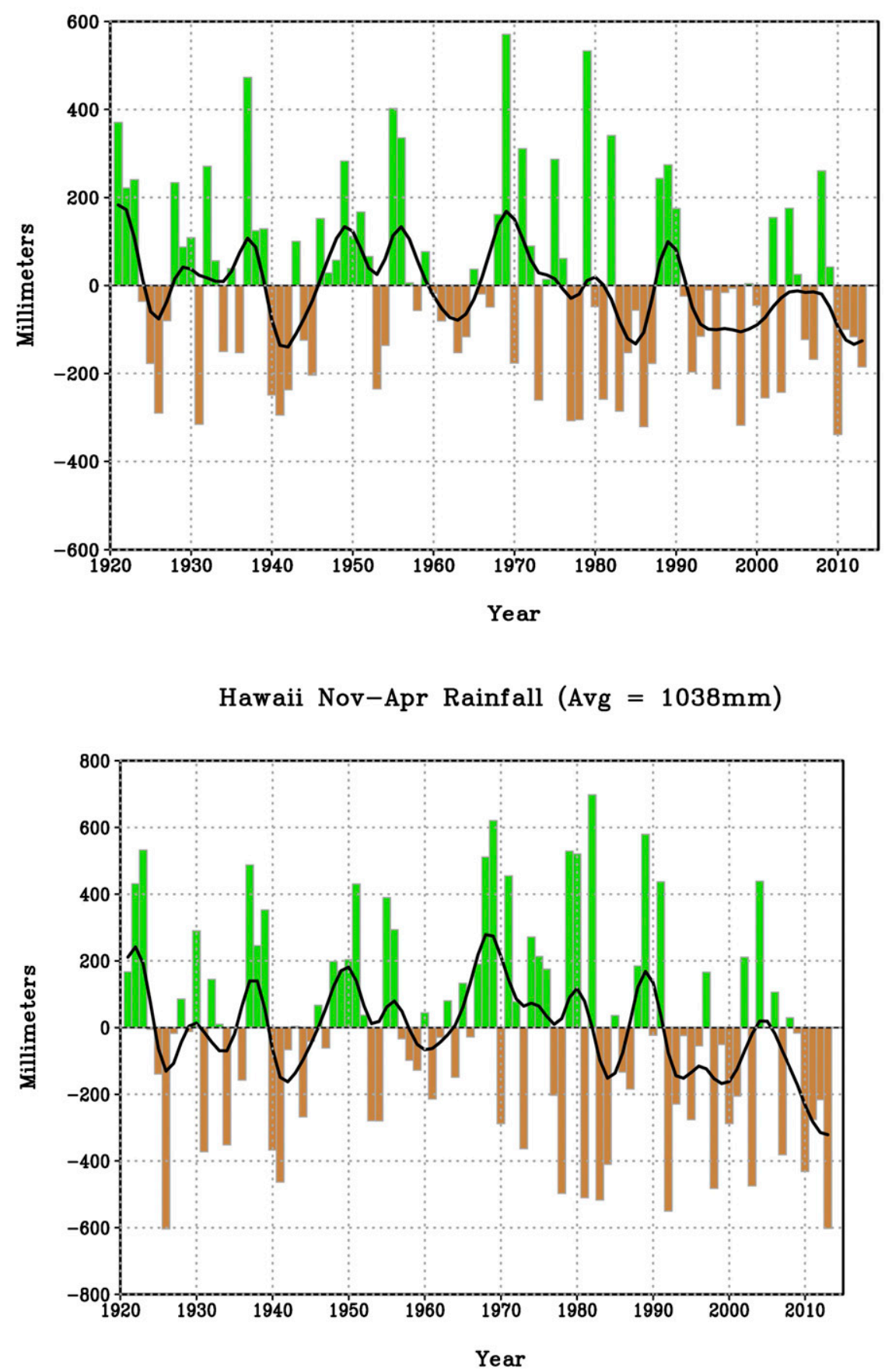

FIG. 2. Time series of Hawaii precipitation (1920-2012) for (top) December-February and (bottom) November-April seasons. The correlation coefficient between the two time series is $r=0.83$, which is highly statistically significant $(p>0.99)$.

this method, the global three-dimensional field of the atmospheric circulation could theoretically be reconstructed from a global network of proxy records that were capable of constraining the atmospheric circulation globally. However, since we are using only proxy records from a limited region of the North American southwest, the reconstruction will display skill largely in the regions where the atmospheric 
TABLE 1. Summary of terms and acronyms used in the paper, including data type, sources, and citation.

\begin{tabular}{|c|c|c|c|}
\hline Acronym & Description & Type of proxy record & Reference \\
\hline NADA & North American drought atlas & Tree rings & Cook et al. (2007) \\
\hline WY & $\begin{array}{l}\text { Western U.S. water-year precipitation } \\
\text { (October-September) }\end{array}$ & $\begin{array}{l}\text { Reconstructed WY precipitation for the } \\
\text { western United States using tree-ring } \\
\text { reconstructed streamflow records }\end{array}$ & Diaz and Wahl (2015) \\
\hline FM & $\begin{array}{l}\text { Reconstructed February-March temperature } \\
\text { for western United States }\end{array}$ & Tree rings & Wahl et al. (2014) \\
\hline rSLP & Reconstructed SLP & Proxy-based analogs & This paper \\
\hline iSLP & Assimilated (observed) SLP & Twentiety-Century Reanalysis & Compo et al. (2011) \\
\hline uSLP & Observationally based SLP & Met Office & Allan and Ansell (2006) \\
\hline MPI-ESM-P & $\begin{array}{l}\text { Max Planck Institute climate model used to } \\
\text { simulate/reconstruct preinstrumental SLP }\end{array}$ & Model reconstructed SLP fields & Giorgetta et al. (2013) \\
\hline
\end{tabular}

circulation most strongly influences the predictorsnamely, in the region of the NNP and adjacent western North America (cf. Diaz and Wahl 2015, their Figs. 2, 4, and 7; St. George et al. 2010; Wahl and Smerdon 2012).

The three predictors' fields and the simulated fields were regridded to the original NADA grid ( 2.5 degrees longitude $\times 2.5$ degrees latitude) and renormalized to ensure that each of the three predictors contributed equally to the measure of similarity between the predictor fields and the simulated fields. The Euclidian distance metric (Matulla et al. 2008; Gavin et al. 2003) was used to characterize the closeness of the model and paleoclimate states. The squared chord distance metric was also evaluated since it has shown optimizing properties in other analog-based paleoclimate reconstruction processes (Gavin et al. 2003), but it performed similarly to the Euclidian metric, which is used here.

In this study, we focus on the reconstructed SLP field in the DJF season. The reconstruction is generally not optimally based on a single, nearest-neighbor analog, which runs a significant risk of leaving out skillenhancing information from the other near-neighbor analogs (Wahl 2004). Here, we estimated an optimal number of analogs based on analysis of minimum RMSE in self-reconstruction (reconstruction of model SLP in the NNP and adjacent North America using model soil moisture, FM temperature, and WY precipitation from western North America in place of the proxy-based predictors) across the 30 nearest potential analogs. In this analysis, the target year is excluded from the pool of possible analogs because otherwise the target year would be identified as an analog of itself. The mean SLP of the closest 15 analog years was selected by this process and computed as the analog state for each DJF season between 1500 and 1980, the period over which the predictor data are generally available. Once determined, the analog-based reconstructions of SLP were then regridded to a $2.0^{\circ}$ grid to estimate their spatial skill during the period 1930-80 in comparison to the
Twentieth-Century Reanalysis (20CRv2; Compo et al. 2011; iSLP). The skill measured by Pearson's correlation ranges to nearly 0.7 and is concentrated in the NNP and far-western North America (Fig. 3), directly upstream of the regions covered by the predictor fields and generally encompassing the important synoptic circulation features affecting Hawaii rainfall (Fig. 1). A scatterplot of rSLP versus iSLP over the calibration period 1921-80 (described below) is shown in Fig. 4, taken as an index over the NNP region utilized in this study (Fig. 3). The agreement between the two SLP index series is good, though somewhat modest $(r=0.625)$. Additional details of the analog methodology, including the spatial domains of the proxy-based predictor data, are provided in the supplemental material.

\section{b. Reconstruction of Hawaii rainfall}

As discussed above, rainfall values for Hawaii (HIrain) are based on the dataset developed by Frazier et al. (2016). Time series of HI-rain for DJF and NovemberApril (the nominal wet season) are shown in Fig. 2. The mean DJF rainfall over the available observational record for the state of Hawaii as a whole is $\sim 500 \mathrm{~mm}$ (Table 2). We note that at both interannual and decadal time scales the impact of sea surface temperature in the tropical Pacific is well represented in the regional precipitation around the Hawaiian Islands (DG12). To illustrate this feature, Fig. 5 shows the spatial pattern of changes in precipitation in a region around the Hawaiian Islands, between two strong El Niño and La Niña events (Fig. 5, top) and the pattern corresponding to two decadal-scale periods with relatively warm versus relatively cool tropical Pacific SSTs based on the NCEPNCAR reanalysis dataset (Kistler et al. 2001).

Indices of iSLP and rSLP were both used in linear regression calibrations against HI-rain over the period 1921-80. The year 1921 is the farthest back in time that HI-rain is continuously representative of the seven main Hawaiian Islands, and 1980 is the most recent year the 

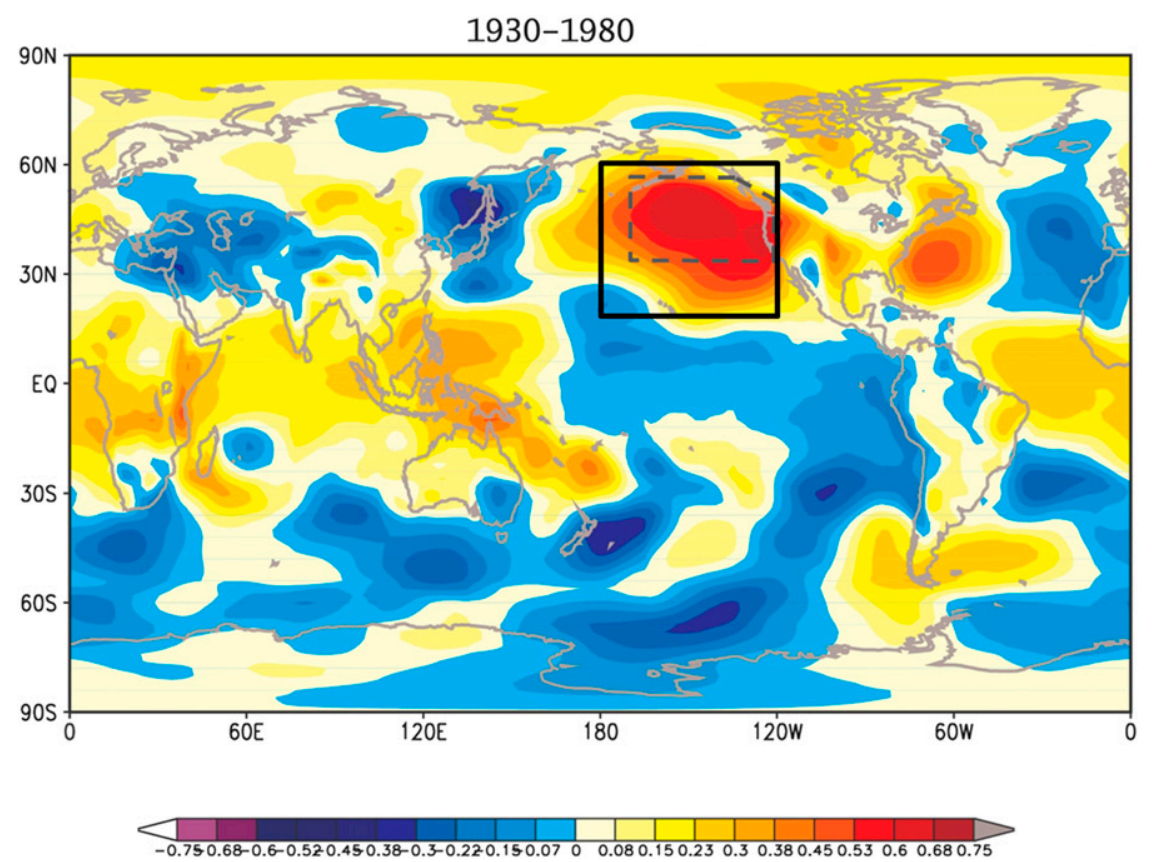

FIG. 3. Linear correlation coefficient between the reconstructed SLP fields and the corresponding 20CRv2 grids, calculated over the time interval 1930-80. Dashed polygon encloses the area used to derive the rSLP, iSLP, and uSLP indices (see text); solid polygon identifies the larger region shown for the maps presented in Fig. 1.

reconstruction data underlying rSLP are available. Since the intercept and slope of the two calibrations are nearly identical (Fig. 6), it was decided that the rSLP-based calibration equation could be used for the primary reconstruction of HI-rain. The rSLP reconstruction for each season is the mean of 15 analogs (cf. section 2a); therefore, its variance is smaller than iSLP since the 55 individual members of 20CRv2 are likely to be more strongly positively correlated than the 15 analogs and thus less likely to cancel each other in the ensemble mean. The variance of the rSLP-based reconstruction was therefore adjusted to match that of the iSLP-based reconstruction over the 1921-80 calibration period as follows: 1) the ratio of standard deviations of the iSLPto rSLP-based anomalies (from their 1921-80 means) was calculated (2.048), 2) the rSLP-based anomalies were multiplied by this factor for each year, and 3) this product calculated for each year was added back to the rSLP-based 1921-80 mean. For comparison, both the rSLP- and iSLP-based reconstructions are shown in Fig. 7.

We performed a comparison of the iSLP- and rSLPbased reconstructions with the goal of independent evaluation of the rSLP-based fit during the period 18721920 and noted the systematic divergence between the two estimates during that time (Fig. 7). In light of this divergence, we conducted a set of analyses, which lead us to conclude that the rSLP-based reconstruction is more representative of what actually occurred during this time period and that the iSLP-based reconstruction is more likely to be less representative. Thus, we were not able to utilize the iSLP-based reconstruction as an independent evaluator for the quality of the rSLP-based fit during this precalibration period. The details of this evaluation and related validation information are provided in the supplemental material, along with a description of the methodology we used to estimate reconstruction uncertainty.

\section{Analysis}

Figure 7 contains a number of prominent features that will be evaluated here by comparison with other independent climate reconstructions relevant to Hawaiian climate variability. A major drought episode is reconstructed in the preinstrumental period for the interval $\sim 1756-74$, when all the years are below the long-term median and 13 out of 19 years are below the first quartile. The driest reconstructed nominal decade is 1761-70, just before the first European contact. This time represents the culmination of a long-term drying trend from the start of our reconstruction in $1500 \mathrm{CE}$. A new paleoecological study (Crausbay 2011) shows the presence of cloud forest above $2300 \mathrm{~m}$ around Flat Top Bog, Haleakala, Maui for 
$1921-1980$

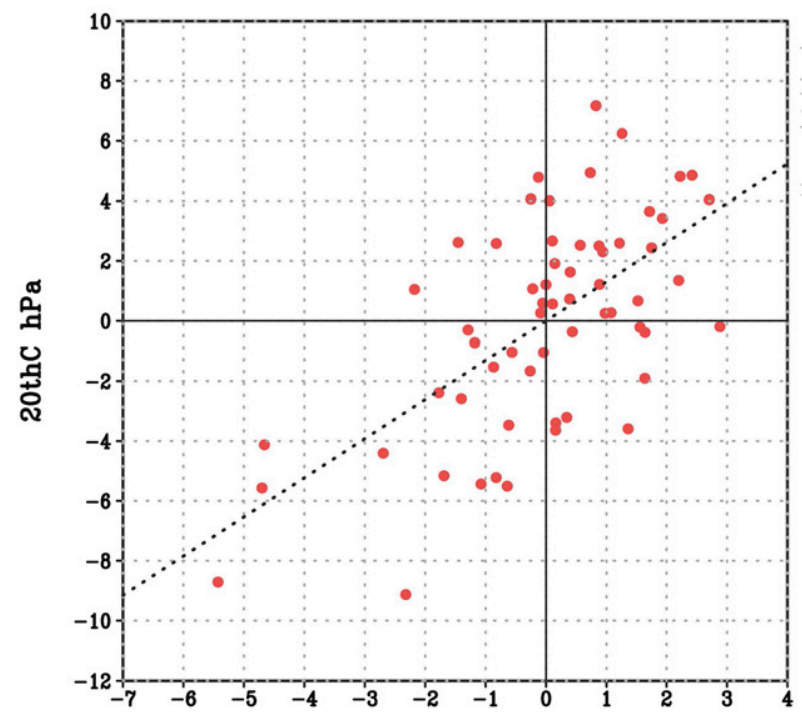

FIG. 4. Scatter diagram between an index of the NE Pacific spatial domain reconstructed SLP ( $x$ axis; hPa) and the equivalent index calculated from $20 \mathrm{CRv} 2$ (iSLP) dataset. It shows that the observationally based data and the reconstructed SLP fields are reasonably well correlated $(r=0.625, p>0.99)$ over the calibration interval 1921-80.

the period $\sim 1500-1730 \mathrm{CE}$. The cloud forest has been absent above that elevation since then, suggesting a lower trade wind inversion and, hence, a generally drier climate in the region compared with the period ending around $1730 \mathrm{CE}$.

A rainfall reconstruction by Pau et al. (2012) based on a pollen abundance index from the island of Maui suggests a decline in rainfall from the medieval period $(\sim 950-1250 \mathrm{CE})$ to around the mid-1700s CE. Archeological evidence indicates that Hawaiian settlement underwent a period of expansion from windward areas with abundant surface water resources to drier leeward areas during approximately 1450 to $\sim 1800$ (Kirch et al. 2009). Our rainfall reconstruction suggests that this period, or at least the 1500-1780 portion, was one of generally declining rainfall, marked by a long very dry interval centered around the 1760s. This period of low rainfall immediately preceded the time of the first European contact (1778). The succeeding 75 years, ending around 1850 , generally saw relatively abundant rainfall. The settlement of leeward areas of the islands by Hawaiians necessitated the development of dryland farming technology that produced large rainfed field systems in Kalaupapa (Moloka'i), Kaupō (leeward Haleakalā, Maui), Kohala and Waimea (northern Hawaii), and Kona (western Hawaii; Kirch et al. 2009). These field systems fell into disuse during the early nineteenth century, probably because of the precipitous decline in
TABLE 2. Statistical summary of reconstructed and observed Hawaii rainfall for the 3 months of December-February for different time periods. The superscript " $r$ " indicates a reconstructed value based on the reconstructed SLP field. The superscript " $i$ " indicates value is reconstructed from the "observed" $20 \mathrm{CRv} 2$ dataset. The superscript " $o$ " gives values based on the Hawaiian station data from Frazier et al. (2016).

\begin{tabular}{lcc}
\hline \hline Time period & $\begin{array}{c}\text { Average } \\
\text { rainfall }(\mathrm{mm})\end{array}$ & $\begin{array}{r}\text { Variance adjusted } \\
\text { std dev }(\mathrm{mm})\end{array}$ \\
\hline $1500-1980^{r}$ & 641 & 167 \\
$1500-1650^{r}$ & 681 & 158 \\
$1651-1760^{r}$ & 614 & 165 \\
$1761-1850^{r}$ & 676 & 176 \\
$1851-1980^{r}$ & 591 & 157 \\
$1872-1980^{r}$ & 578 & 144 \\
$1872-1980^{i}$ & 501 & 157 \\
$1872-1920^{i}$ & 457 & 117 \\
$1921-80^{i}$ & 537 & 154 \\
$1921-80^{\circ}$ & 537 & 219 \\
$1981-2012^{i}$ & 492 & 171 \\
$1981-2012^{\circ}$ & 447 & 191 \\
$1921-2012^{\circ}$ & 506 & 213 \\
\hline
\end{tabular}

the native Hawaiian population during that time due mainly to introduced diseases. Our reconstruction suggests that variations in rainfall were not major factors in the chronology of development and decline of these Hawaii dryland field systems. The impressive development of these dryland agricultural systems occurred during a period of generally declining rainfall and was abandoned during a period of relatively abundant rains.

As both individual El Niño and La Niña years, as well as multidecadal shifts in the PDO, tend to be reflected in anomalous rainfall totals in the Hawaiian Islands (DG12), we have relied here on the work of Gergis and Fowler (2006, 2009, hereafter GF06 and GF09) for information on ENSO activity prior to the late 1800s. The period from the late 1500 s to the late 1700 s is reconstructed by GF09 (cf. their Fig. 5) as one in which ENSO activity increased toward a relative peak in El Niño activity during the early decades of the 1700s. Some of the driest winters in the first half of our reconstruction occurred from 1738 to 1741 , following an extreme El Niño event in 1737 as given in GF06 (cf. Table 2). Some of the wettest winters in that part of our record occur in the 1500s and early decades of the 1600s. As shown in Table 3 of GF06 during that period there appears to have been a preponderance of La Niña events compared to El Niños. This is consistent with the results from other studies of changes in Hawaiian Islands rainfall as discussed above.

A rather dramatic increase in reconstructed mean winter rainfall occurred around 1775, with a period of very high values following the earlier drought decades. The highest reconstructed winter rainfall value occurs in 
NCEP/NCAR Reanalysis
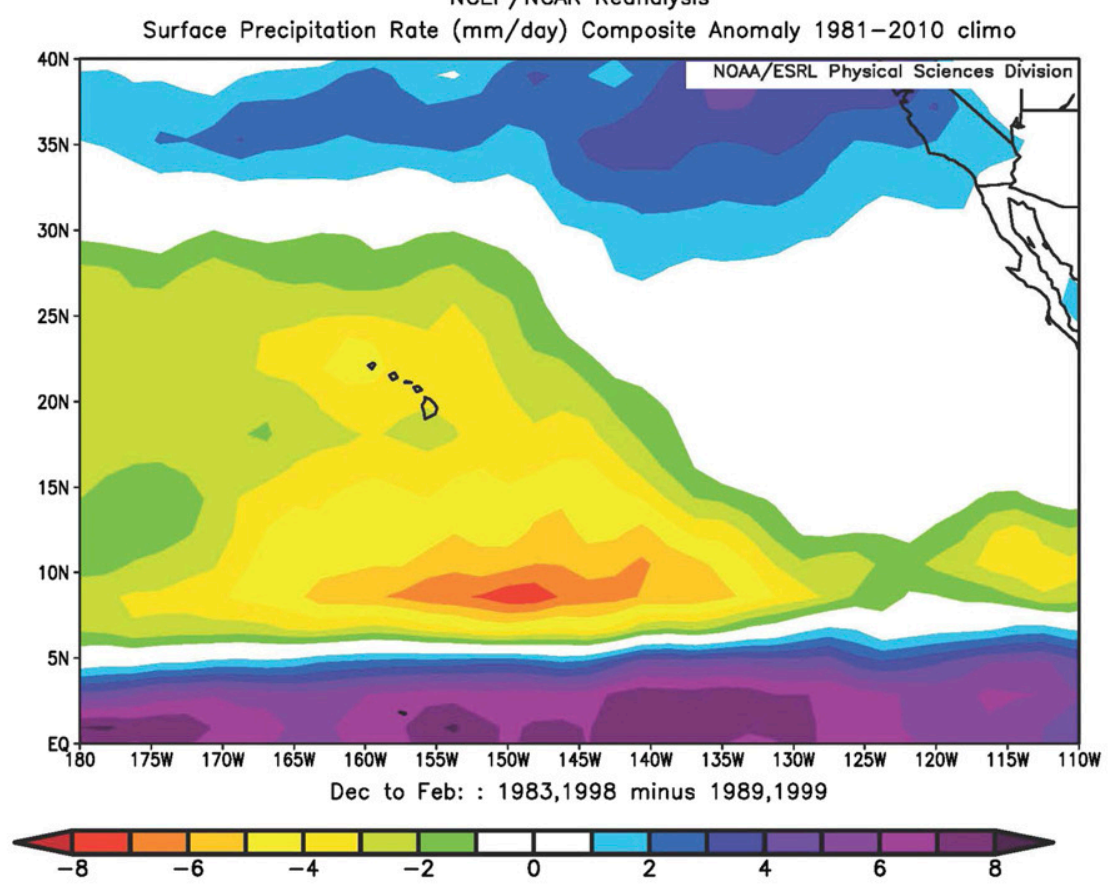

NCEP/NCAR Reanalysis

Surface Precipitation Rate (mm/day) Composite Anomaly 1981-2010 climo
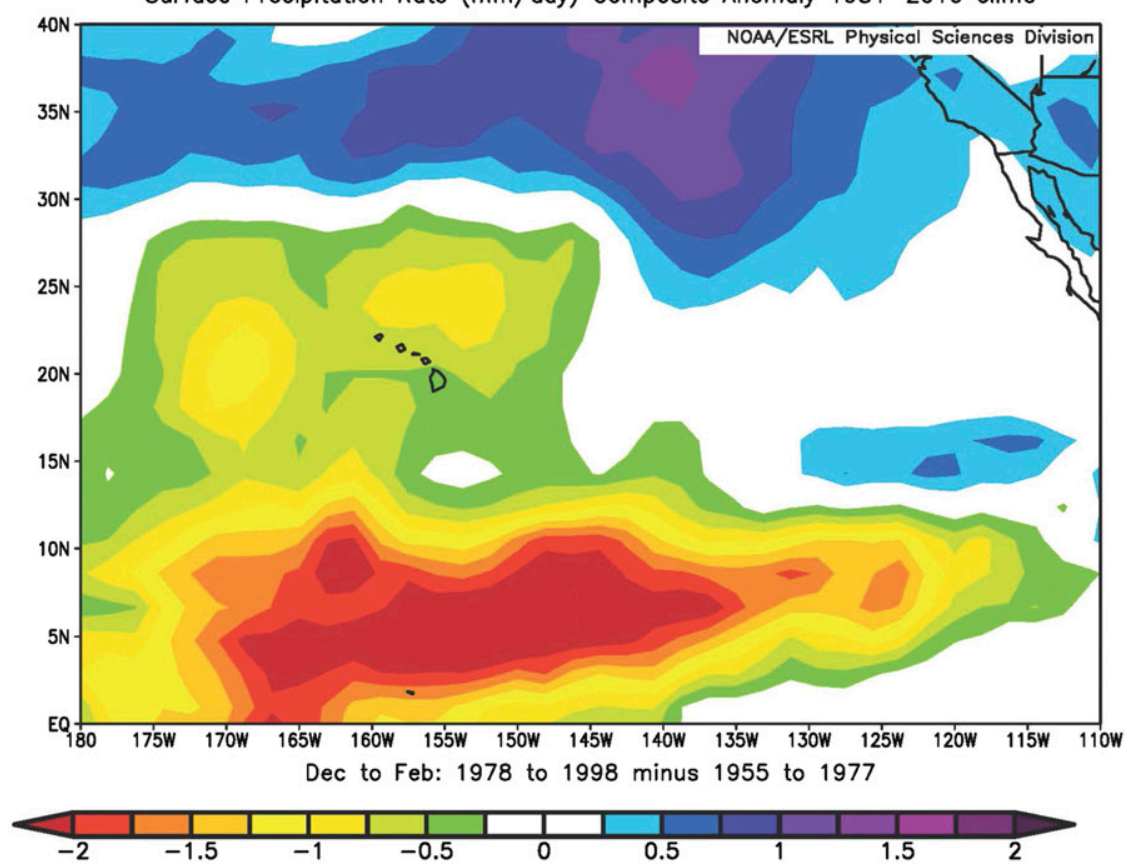

FIG. 5. Difference in DJF precipitation in a broad region around the Hawaiian Islands. (top) Difference associated with two strong El Niño and La Niña events. (bottom) Difference associated with warm vs cool decadal-scale SST or for different PDO phases. Note the difference in scale. 

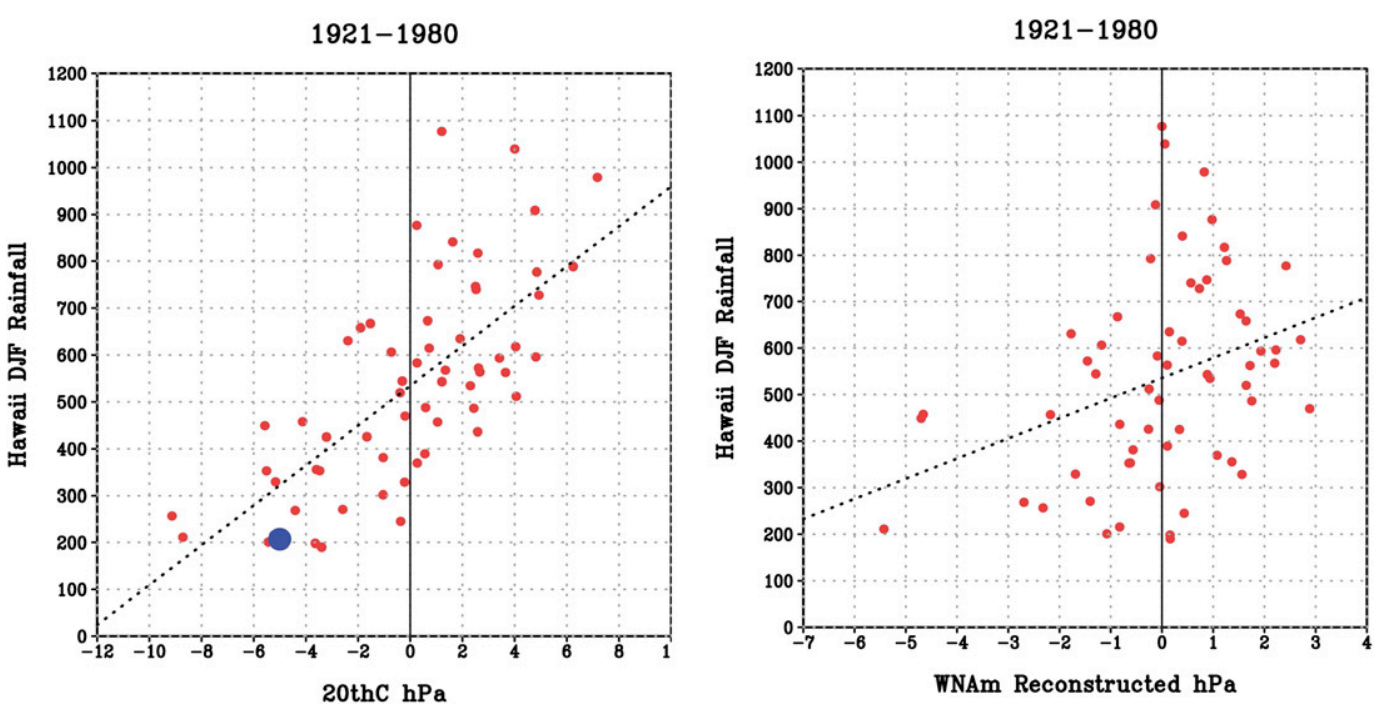

FIG. 6. Scatterplot between Hawaii DJF rainfall and (left) iSLP (correlation coefficient is $r=0.71, N=61, p>$ 0.99 ) and (right) rSLP (correlation coefficient is $r=0.34, N=61, p>0.95$ ). As expected, correlations with rSLP are lower, but we adjust for the loss of variance as described in the text. The blue dot in (left) represents the corresponding estimated rainfall value for the DJF 2015/16 season. Note that this value was not included in the scatter diagram and calculation of the linear parameters or correlation value above. Note the difference in the scale in the $x$ axis of the two panels.

1781 , and the 1781-90 decade is the wettest in our record (Table 2). The period from 1777 to 1783 is the rainiest such interval in the reconstruction. It is worth pointing out that during that time there were no major El Niños evident in the compilation by GF06 (cf. their Table 2). Another extended rainy period occurred over the years $1828-50$ with 21 of 23 years above the median and 16 of 23 above the third quartile. A calendar decade version of Fig. 7 is given as Fig. S5.

An overall drying trend is indicated after the $1850 \mathrm{~s}$ (Fig. 7). This trend amounts to $\sim 1.3 \mathrm{~mm} \mathrm{yr}^{-1}$, a change of $170 \mathrm{~mm}$ or $\sim 27 \%$ of the reconstructed mean DJF rainfall of $641 \mathrm{~mm}$. The recent decades have been particularly dry with reconstructed values in the period 1954-80 showing 22 of 27 years below the long-term median-all 5 decades from 1931 to 1980 are among the 10 driest. The instrumental record (Fig. 2) also shows that dryness continued during the 34 years since the end of the rSLP reconstruction. Coincidentally, a very strong El Niño event developed during the period when we were completing our study. This afforded us an opportunity to compare our results with one additional independent value of mean DJF rainfall for Hawaii and the corresponding index of SLP anomaly over the target regions shown in Fig. 3. For a current operational network of 136 stations with climatological mean (19812010) DJF rainfall averaged over all the stations of $475 \mathrm{~mm}$, the 2015/16 DJF rainfall averaged $193 \mathrm{~mm}$, $\sim 41 \%$ of the climatological value (data provided by the
National Weather Service Office in Honolulu, courtesy of Kevin Kodama). The average of the individual station anomalies was $\sim 32 \%$ of normal-indeed, one of the driest winters on record. Using the data from Frazier et al. (2016) and the $41 \%$ fraction for the $1920-80$ mean, the estimated value came out to $207 \mathrm{~mm}$ and is matched with an SLP index value of $-5 \mathrm{hPa}$ (the blue dot shown in the left panel of Fig. 6).

\section{Summary and discussion}

We have developed a statewide winter (DJF) rainfall reconstruction for Hawaii based on its relationship to sea level pressure in the North Pacific. A new reconstruction index of North Pacific SLP was developed, as described in cection $2 \mathrm{a}$, which was used in turn to drive the rainfall reconstruction. The most salient feature of the reconstructed statewide average winter rainfall since $1500 \mathrm{CE}$ is the long-term decline that takes place over time, which contains several multidecadal periods of increases and decreases in precipitation (Figs. 7 and S5). The rainfall response to changes in the North Pacific large-scale circulation is consistent with long-term changes in tropical Pacific SST based on both direct reconstruction of ENSO region SST (Emile-Geay et al. 2013) and a unified ENSO index (McGregor et al. 2010), as well as from individual El Niño/La Niña event frequency reconstructions (DG12; GF06; GF09). 

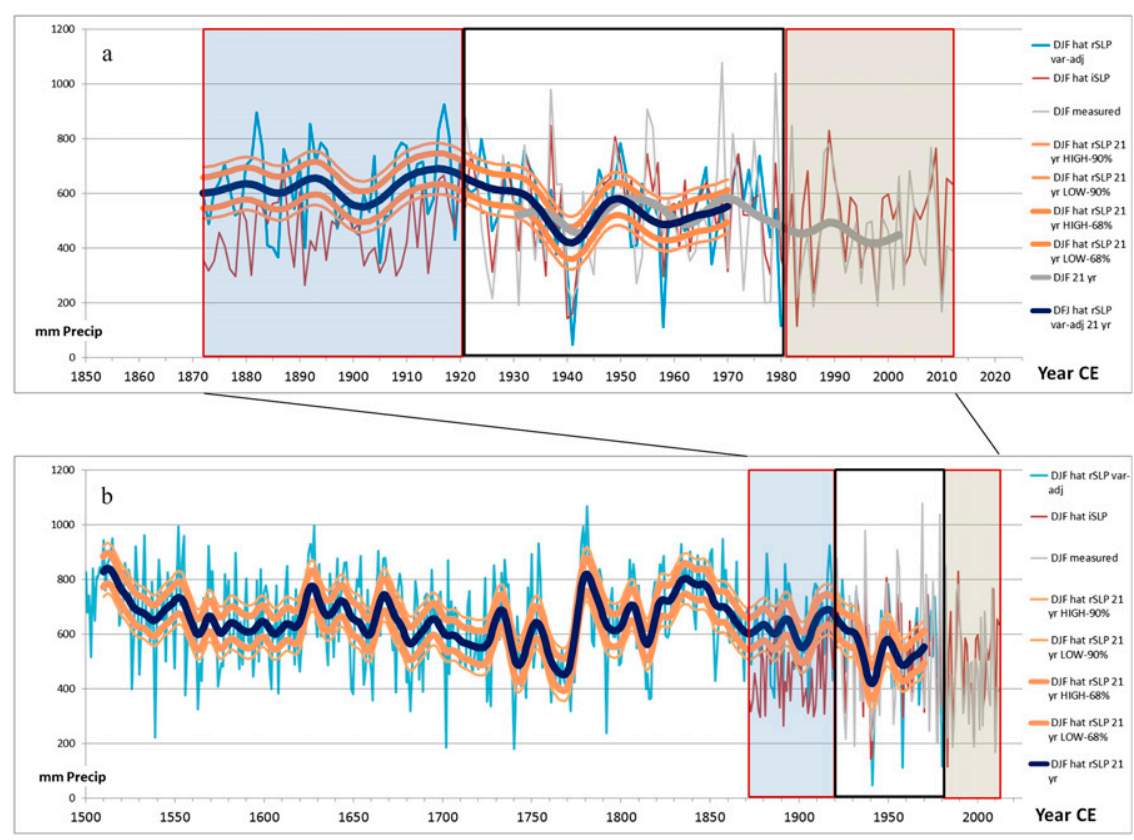

FIG. 7. Reconstruction of Hawaii DJF rainfall back to 1500, based on the instrumental Hawaii precipitation index (gray) calibrated against both iSLP (red) and rSLP (blue) predictor data, following methodology described in the text. (top) Period 1872-2012 during which there is continuous iSLP data. (bottom) Full reconstruction period. Outlined boxes in both panels show the 1872-1920, 1921-80 (calibration), and 1981-2012 periods, from left to right. Smoothed curves are 21-yr Gaussian-weighted moving averages, as noted in the figure legends; the orange smoothed curves show the $68 \%$ (heavy line) and $90 \%$ (light line) uncertainty range estimates described in the supplemental material. Metrics of calibration are given in the caption for Fig. 6; the standard error of prediction for the rSLP reconstruction during the calibration period is $242 \mathrm{~mm}$.

The general drying trend is also coherent with the drying trend present in the observational record available from 1920 to 2012. As documented in DG12 and references therein, Hawaiian Islands winter rainfall exhibits a strong association with ENSO (drier El Niño/ wet La Niña) throughout the instrumental record. The association of Hawaii winter rainfall with SLP in the North Pacific resulting in wetter conditions during weak low pressure near the Gulf of Alaska, and vice versa when low pressures are enhanced, also correlates with relatively lower surface temperatures in the ENSO regions (Hoerling and Kumar 2000; Diaz et al. 2001).

Paleoclimatic reconstruction studies have documented the presence of extensive decadal and longerterm variations in North Pacific circulation features (e.g., MacDonald and Case 2005; Wise and Dannenberg 2014) that support the idea that over the past few centuries alternating strong and weak pressure field anomalies have occurred over this region. Such large-scale changes in North Pacific pressure patterns have led to significant recent changes in hydroclimatic variables all along the west coast of North America (Belmecheri et al. 2016; Diaz and Wahl 2015; Griffin and Anchukaitis
2014). A study by Moore et al. (2004) also compares favorably with our results, indicating a long-term increase in snow accumulation at Mount Logan, British Columbia, in western Canada, as does that of Osterberg et al. (2014), also using a Mount Logan ice core profile, both of whom found a strong association between snow accumulation and the strength of the Gulf of Alaska low pressure system.

The implication for a long-term intensification of low pressure systems in the Gulf of Alaska (see also Graham and Diaz 2001) is consistent with the inferred changes in Hawaiian rainfall over the past several centuries (see DG12). Support for our focus on SLP variability in the northeast Pacific region is indicated by the strong (negative) correlation between Honolulu DJF rainfall and areas in western North America, particularly over western Canada (Fig. 8). Figures 7 and S5 exhibit significant fluctuations on multidecadal and -century time scales, which is reflected in the variance spectrum shown in Fig. 9. Two long periods of decline, a $\sim 250$-yr decline starting around 1500 and a $\sim 160$-yr decline starting around 1850, are evident. In between these periods DJF precipitation is inferred to have increased. The slope of 


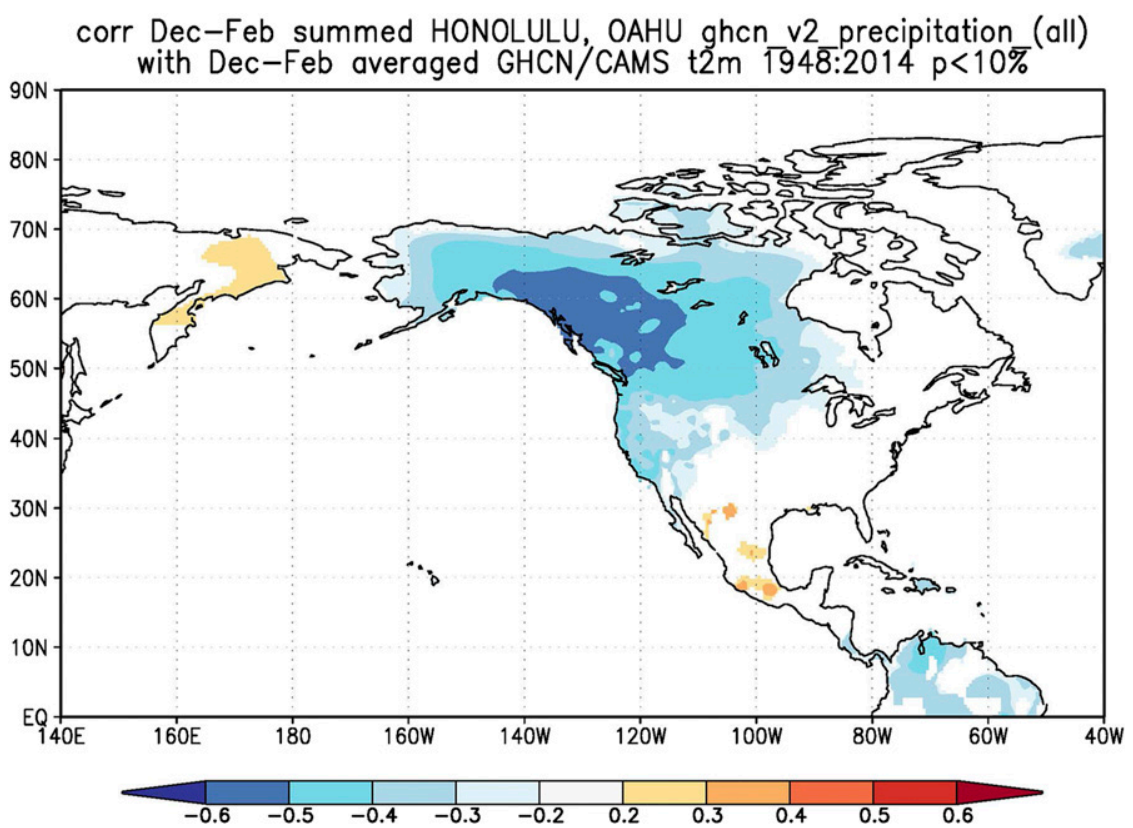

FIG. 8. Correlation pattern between DJF rainfall at Honolulu, Hawaii and corresponding values in the North American sector over the period 1948-2014.

the linear regression line for the entire period is $0.24 \mathrm{~mm} \mathrm{yr}^{-1}$, which amounts to a decrease of around $113 \mathrm{~mm}$ in seasonal rainfall.

The hydrological significance of the long-term precipitation decrease can be assessed by estimating its effect on streamflow. Based on the linear trend line, DJF precipitation decreased from $697 \mathrm{~mm}$ in the year 1500 to $584 \mathrm{~mm}$ in 1980 . We can make rough estimates of the associated streamflow change using runoff coefficients (streamflow $Q$ divided by precipitation $P$ ) derived by Johnson et al. (2014, their Table 4). Plotting $Q / P$ values versus mean annual precipitation (MAP) for 20 gauged watersheds in Hawaii (not shown) indicates a strong linear relationship between $Q / P$ and MAP $\left(r^{2}=0.64\right)$. We used the $Q / P$ versus MAP relationship to estimate wet season runoff coefficients of 0.26 and 0.21 for basins with MAP corresponding to DJF precipitation of 697 and $584 \mathrm{~mm}$ (MAP estimated using a constant ratio of DJF to annual precipitation of 0.29 , the mean for observed statewide precipitation for 1920-2012). Applying those coefficients to the DJF precipitation for the beginning and end of the period yields a reduction in DJF streamflow of $32 \%$ over the period of the reconstruction. Noting that, while a downward trend in precipitation is evident over the whole period, most of the decline occurred in the last 160 years, we would expect to see declines in streamflow over the instrumental period in Hawaii. Indeed, over the period 1913-2002, Oki (2004) found decreases in total streamflow in six of seven Hawaii streams studied, although only one had a statistically significant decrease. Stream base flow decreased significantly for all seven streams studied, by $18 \%-67 \%$ (average decline of $41 \%$ ) over the 90 -yr study period.

A comparison of California-Nevada (CANV) precipitation by century since the 1500 s reconstructed in Diaz and Wahl (2015) in terms of changes in the frequency of very wet years is consistent with the generally negative association with Hawaiian rainfall illustrated in Fig. 8. The number of years with precipitation in the upper decile in that reconstruction changes from less than 6 in the sixteenth and seventeenth centuries, to 9 in the eighteenth, 12 in the nineteenth, and 11 in the twentieth century.

It is understood that the variance characteristics of the reconstructed rainfall series reflects the underlying variance structure of the SLP predictor variable. Clearly, the magnitude of the DJF rainfall values depends on the strength of the modern calibration as well as the skillfulness of the SLP reconstructions (Fig. 6). But our basic premise is that the changing circulation patterns in the North Pacific reflected in changes in the associated SLP field are major drivers of Hawaiian Islands winter season rainfall. The full DJF rainfall reconstruction shown in Fig. 7 includes measures of uncertainty with respect to bidecadally smoothed values, which were generally deemed to be more illuminating than annual values. We provided context in section $2 \mathrm{~b}$ and the supplemental material for concluding that prior to the 1920s the reconstructed SLP field was 

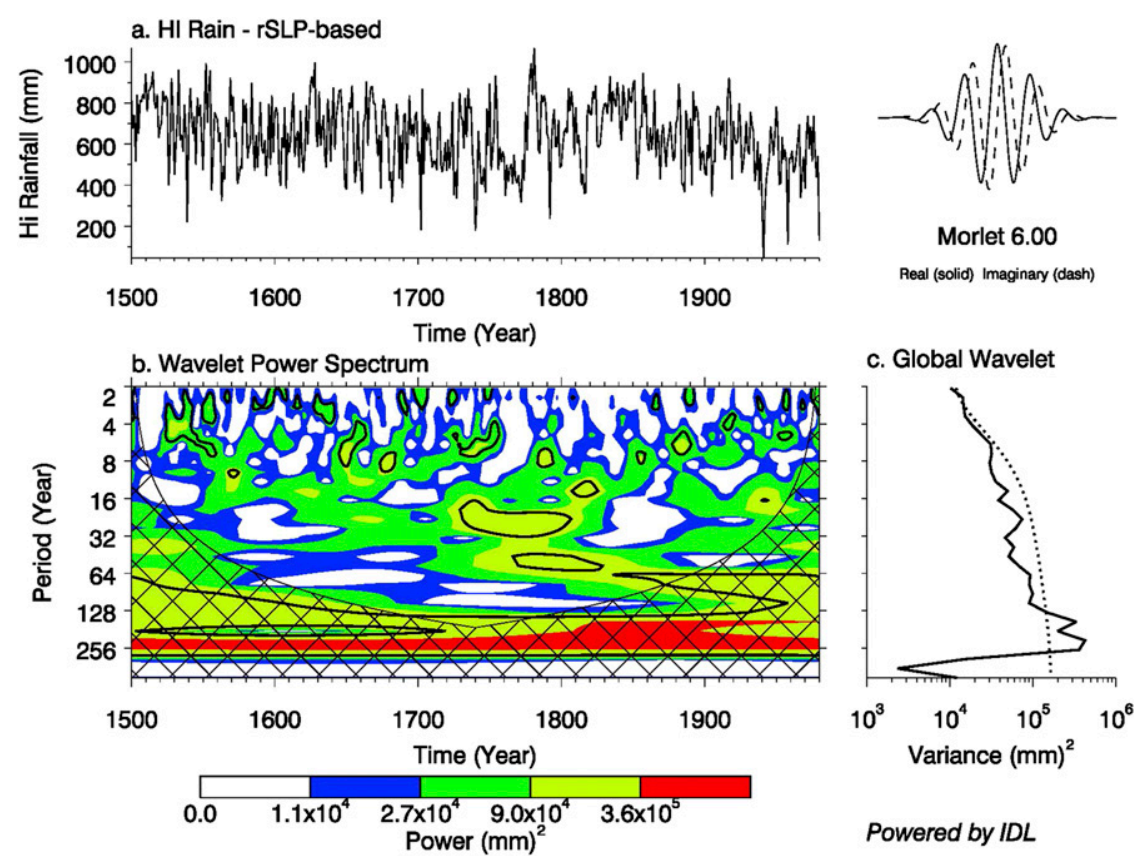

FIG. 9. Wavelet analysis of the reconstructed (1500-1980) plus observed (1981-2012) DJF Hawaii precipitation series. As noted in text, there is significant low-frequency variability throughout the analyzed period (1500-2012).

a better representation of the true SLP field than that obtained from the 20CRv2 dataset (cf. Figs. S1, S3, and S4). In particular, greater data sparsity prior to $\sim 1920$ results in much greater uncertainty in the 20CRv2 data (Fig. S1), particularly prior to 1911 , with sea level pressure values that appear too low compared to the rest of the record.

The reconstructed changes in Hawaii wet season rainfall represent an initial effort to extend the precipitation record for the Islands and additional analysis is warranted. Some caveats worth noting deal with the fact that the anomalous SLP centers in the North Pacific for marked dry and wet years (see Fig. 1) are somewhat displaced from each other. Furthermore, the domain of the reconstructed SLP used to create the rSLP index (Fig. 2), as noted earlier, corresponds to the region of highest correlation with the iSLP index and is more closely collocated with the dry winter pattern (see Fig. 1); thus, it may result in a somewhat better estimation of the dry years compared to the wet years (see Fig. 6, right). However, there is no evidence that there is much difference in the association between wet and dry years based on the 20CRv2 dataset as shown in the left panel of Fig. 6, which is derived from the same region of the NNP (Fig. 3).

The influence of ENSO and the PDO on Hawaiian rainfall has been well demonstrated. The instrumental period data as summarized in Table 2 indicate an overall drying trend, which may be an indication of a longer-term shift toward a drier climate as indicated in our reconstruction. A long-term trend toward warmer equatorial Pacific Ocean (Conroy et al. 2009) would be consistent with the results presented here. Nevertheless, efforts to use additional modes of variability and/ or other climate variables as predictors in the reconstruction process are warranted.

Acknowledgments. ERW's research effort for reconstruction of NNP sea level pressure was partially supported by the Cluster of Excellence CLISAP (Hamburg, Germany). We kindly thank Cary Mock for providing us with the plot shown in Fig. 8. We also thank the reviewers for their thorough and constructive reviews that helped us improve the original manuscript.

The gridded SLP reconstruction for the region used to derive the rSLP index (dashed polygon in Fig. 3) and the Hawaii precipitation reconstruction data will be made available upon publication from NOAA Paleoclimatology/ World Data Service for Paleoclimatology (https://www.ncdc. noaa.gov/data-access/paleoclimatology-data). Both datasets cover the reconstruction periods evaluated and used here, 1500-1980 CE.

\section{REFERENCES}

Allan, R., and T. Ansell, 2006: A new globally complete monthly historical gridded mean sea level pressure dataset (HadSLP2): 1850-2004. J. Climate, 19, 5816-5842, doi:10.1175/JCLI3937.1. 
Belmecheri, S., F. Babst, E. R. Wahl, D. W. Stahle, and V. Trouet, 2016: Multi-century evaluation of Sierra Nevada snowpack. Nat. Climate Change, 6, 2-3, doi:10.1038/nclimate2809.

Chu, P.-S., 1989: Hawaiian drought and the Southern Oscillation. Int. J. Climatol., 9, 619-631, doi:10.1002/joc.3370090606.

— , and H. Chen, 2005: Interannual and interdecadal rainfall variations in the Hawaiian Islands. J. Climate, 18, 4796-4813, doi:10.1175/JCLI3578.1.

Compo, G. P., and Coauthors, 2011: The Twentieth Century Reanalysis Project. Quart. J. Roy. Meteor. Soc., 137, 1-28, doi:10.1002/qj.776.

Conroy, J. L., A. Restrepo, J. T. Overpeck, M. Steinitz-Kannan, J. E. Cole, M. B. Bush, and P. A. Colinvaux, 2009: Unprecedented recent warming of surface temperatures in the eastern tropical Pacific Ocean. Nat. Geosci., 2, 46-50, doi:10.1038/ngeo390.

Cook, E. R., R. Seager, M. A. Cane, and D. W. Stahle, 2007: North American drought: Reconstructions, causes, and consequences. Earth-Sci. Rev., 81, 93-134, doi:10.1016/ j.earscirev.2006.12.002.

Crausbay, S. D., 2011: Vegetation-climate relationships across space and time at high elevation in Hawai'i. Ph.D. dissertation, Dept. of Botany, University of Wisconsin-Madison, $186 \mathrm{pp}$

Diaz, H. F., and T. W. Giambelluca, 2012: Changes in atmospheric circulation patterns associated with high and low rainfall regimes in the Hawaiian Islands region on multiple time scales. Global Planet. Change, 98-99, 97-108, doi:10.1016/ j.gloplacha.2012.08.011.

_ , and E. R. Wahl, 2015: Recent California water year precipitation deficits: A 440-year perspective. J. Climate, 28 4637-4652, doi:10.1175/JCLI-D-14-00774.1.

_ - M. P. Hoerling, and J. K. Eischeid, 2001: ENSO variability, teleconnections, and climate change. Int. J. Climatol., 21, 1845-1862, doi:10.1002/joc.631.

Elison Timm, O., T. W. Giambelluca, and H. F. Diaz, 2015: Statistical downscaling of rainfall changes in Hawai' $i$ based on the CMIP5 global model projections. J. Geophys. Res. Atmos., 120, 92-112, doi:10.1002/2014JD022059.

Emile-Geay, J., K. M. Cobb, M. E. Mann, and A. T. Wittenberg, 2013: Estimating central equatorial Pacific SST variability over the past millennium. Part II: Reconstructions and implications. J. Climate, 26, 2329-2352, doi:10.1175/ JCLI-D-11-00511.1.

Frazier, A. G., T. W. Giambelluca, H. F. Diaz, and H. L. Needham, 2016: Comparison of geostatistical approaches to spatially interpolate month-year rainfall for the Hawaiian Islands. Int. J. Climatol., 36, 1459-1470, doi:10.1002/joc.4437.

Gavin, D. G., W. W. Oswald, E. R. Wahl, and J. W. Williams, 2003: A statistical approach to evaluating distance metrics and analog assignments for pollen records. Quat. Res., 60, 356-367, doi:10.1016/S0033-5894(03)00088-7.

Gergis, J. L., and A. M. Fowler, 2006: How unusual was late 20th century El Niño-Southern Oscillation (ENSO)? Assessing evidence from tree-ring, coral, ice-core and documentary palaeoarchives, A.D. 1525-2002. Adv. Geosci., 6, 173-179, doi:10.5194/adgeo-6-173-2006.

— , and 2009: A history of ENSO events since A.D. 1525: Implications for future climate change. Climatic Change, $\mathbf{9 2}$, 343-387, doi:10.1007/s10584-008-9476-z.

Giambelluca, T. W., Q. Chen, A. G. Frazier, J. P. Price, Y.-L. Chen, P.-S. Chu, J. K. Eischeid, and D. M. Delparte, 2013: Online rainfall atlas of Hawai'i. Bull. Amer. Meteor. Soc., 94, 313-316, doi:10.1175/BAMS-D-11-00228.1.
Giorgetta, M. A., and Coauthors, 2013: Climate and carbon cycle changes from 1850 to 2100 in MPI-ESM simulations for the Coupled Model Intercomparison Project phase 5. J. Adv. Model. Earth Syst., 5, 572-597, doi:10.1002/jame.20038.

Goosse, H., and Coauthors, 2015: Continental-scale temperature variability in PMIP3 simulations and PAGES $2 \mathrm{~K}$ regional temperature reconstructions over the past millennium. Climate Past, 11, 1673-1699, doi:10.5194/cp-11-1673-2015.

Graham, N. E., and H. F. Diaz, 2001: Evidence for intensification of North Pacific winter cyclones since 1948. Bull. Amer. Meteor. Soc., 82, 1869-1893, doi:10.1175/1520-0477(2001)082<1869: EFIONP $>2.3 . \mathrm{CO} ; 2$.

Griffin, D., and K. J. Anchukaitis, 2014: How unusual is the 2012 2014 California drought? Geophys. Res. Lett., 41, 9017-9023, doi:10.1002/2014GL062433.

Hoerling, M. P., and A. Kumar, 2000: Understanding the predicting extratropical teleconnections related to ENSO. El Niño and the Southern Oscillation: Multiscale Variability and Global and Regional Impacts, H. F. Diaz and V. Markgraf, Eds., Cambridge University Press, 57-88.

Johnson, A. G., J. A. Engott, and M. Bassiouni, 2014: Spatially distributed groundwater recharge estimated using a waterbudget model for the island of Maui, Hawai'i, 1978-2007. U.S. Geological Survey Scientific Investigations Rep. 2014-5168, 53 pp., doi:10.3133/sir20145168.

Kirch, P. V., J. Holson, and A. Baer, 2009: Intensive dryland agriculture in Kaupo, Maui, Hawaiian Islands. Asian Perspect., 48, 265-290, doi:10.1353/asi.2009.0006.

Kistler, R., and Coauthors, 2001: The NCEP-NCAR 50-Year Reanalysis: Monthly means CD-ROM and documentation. Bull. Amer. Meteor. Soc., 82, 247-267, doi:10.1175/ 1520-0477(2001)082<0247:TNNYRM>2.3.CO;2.

Kodama, K., and G. M. Barnes, 1997: Heavy rain events over the south-facing slopes of Hawaii: Attendant conditions. Wea. Forecasting, 12, 347-367, doi:10.1175/1520-0434(1997)012<0347: HREOTS $>2.0 . \mathrm{CO} ; 2$.

Longman, R. J., H. F. Diaz, and T. W. Giambelluca, 2015: Sustained increases in lower-tropospheric subsidence over the central tropical North Pacific drives a decline in high-elevation precipitation in Hawaii. J. Climate, 28, 8743-8759, doi:10.1175/ JCLI-D-15-0006.1.

MacDonald, G. M., and R. A. Case, 2005: Variations in the Pacific decadal oscillation over the past millennium. Geophys. Res. Lett., 32, L08703, doi:10.1029/2005GL022478.

Matulla, C., X. Zhang, X. L. Wang, J. Wang, E. Zorita, S. Wagner, and $H$. von Storch, 2008: Influence of similarity measures on the performance of the analog method for downscaling daily precipitation. Climate Dyn., 30, 133-144, doi:10.1007/ s00382-007-0277-2.

McGregor, S. A. T., A. Timmermann, and O. Timm, 2010: A unified proxy for ENSO and PDO variability since 1650. Climate Past, 6, 1-17, doi:10.5194/cp-6-1-2010.

Moore, G. W. K., K. Alverson, and G. Holdsworth, 2004: Mount Logan ice core evidence for changes in the Hadley and Walker circulations following the end of the little ice age. The Hadley Circulation: Present, Past and Future, H. F. Diaz and R. S. Bradley, Eds., Kluwer Academic Publishers, 371-395.

Ohlwein, C., and E. R. Wahl, 2012: Review of probabilistic pollenclimate transfer methods. Quat. Sci. Rev., 31, 17-29, doi:10.1016/j.quascirev.2011.11.002.

Oki, D. S., 2004: Trends in streamflow characteristics at long-term gaging stations, Hawaii. U.S. Geological Survey Scientific Investigations Rep. 2004-5080, 116 pp. 
Osterberg, E. C., P. A. Mayewski, D. A. Fisher, K. J. Kreutz, K. A. Maasch, S. B. Sneed, and E. Kelsey, 2014: Mount Logan ice core record of tropical and solar influences on Aleutian low variability: 500-1998 A.D. J. Geophys. Res. Atmos., 119, 11189-11 204, doi:10.1002/2014JD021847.

Otkin, J. A., and J. E. Martin, 2004: A synoptic climatology of the subtropical Kona storm. Mon. Wea. Rev., 132, 1502-1517, doi:10.1175/1520-0493(2004)132<1502:ASCOTS > 2.0.CO;2.

Pau, S., G. M. MacDonald, and T. W. Gillespie, 2012: A dynamic history of climate change and human impact on the environment from Kealia Pond, Maui, Hawaiian Islands. Ann. Assoc. Amer. Geogr., 102, 748-762, doi:10.1080/ 00045608.2011 .652853

Schenk, F., and E. Zorita, 2012: Reconstruction of high resolution atmospheric fields for northern Europe using analog-upscaling. Climate Past, 8, 1681-1703, doi:10.5194/cp-8-1681-2012.

Schubert, B., 2013: Reconstructing past Hawaiian precipitation using stable carbon isotope analysis of māmane trees. U.S. Geological Survey. [Available online at https://www. sciencebase.gov/catalog/item/54b47aa7e4b0083ed48fad78.]

St. George, S., D. M. Meko, and E. R. Cook, 2010: The seasonality of precipitation signals within the North American Drought Atlas. Holocene, 20, 983-988, doi:10.1177/0959683610365937.

Timm, O., and H. F. Diaz, 2009: Synoptic-statistical approach to regional downscaling of IPCC twenty-first-century climate projections: Seasonal rainfall over the Hawaiian Islands. J. Climate, 22, 4261-4280, doi:10.1175/2009JCLI2833.1.

Wahl, E. R., 2004: A general framework for determining cutoff values to select pollen analogs with dissimilarity metrics in the modern analog technique. Rev. Palaeobot. Palynol., 128, 263 280, doi:10.1016/S0034-6667(03)00137-4.

— , and J. E. Smerdon, 2012: Comparative performance of paleoclimate field and index reconstructions derived from climate proxies and noise-only predictors. Geophys. Res. Lett., 39, L06703, doi:10.1029/2012GL051086.

_ , H. F. Diaz, J. E. Smerdon, and C. M. Ammann, 2014: Late winter temperature response to large tropical volcanic eruptions in temperate western North America: Relationship to ENSO phases. Global Planet. Change, 122, 238-250, doi:10.1016/j.gloplacha.2014.08.005.

Wise, E. K., and M. P. Dannenberg, 2014: Persistence of pressure patterns over North America and the North Pacific since AD 1500. Nat. Commun., 5, 4912, doi:10.1038/ncomms5912.

Zhang, C., Y. Wang, K. Hamilton, and A. Lauer, 2016: Dynamical downscaling of the climate for the Hawaiian Islands. Part I: Present day. J. Climate, 29, 3027-3048, doi:10.1175/JCLI-D-15-0432.1.

Zorita, E., and H. von Storch, 1999: The analog method as a simple statistical downscaling technique: Comparison with more complicated methods. J. Climate, 12, 2474-2489, doi:10.1175/ 1520-0442(1999)012<2474:TAMAAS $>2.0 . C O ; 2$. 